\title{
Nacionalismo y americanismo entre los voluntarios chilenos en el Ejército Libertador de Cuba durante su segunda guerra de independencia (1895-1898) ${ }^{1}$
}

por

Ricardo López Muñoz†

La guerra de independencia de Cuba de 1895-1898 movilizó hacia la isla a un importante contingente de voluntarios chilenos, dispuestos a combatir junto a los insurrectos. A partir de fuentes documentales, periódicas y bibliográficas —cubanas y chilenas-, en el presente artículo se analizan las motivaciones y circunstancias que los convocaron y cómo debieron adaptarse y legitimarse dentro de una guerra que asumieron como propia, no obstante ser extranjeros. Si bien subyace en su partida y sus conductas una cultura americanista, fue la resignificación del renovado nacionalismo surgido en la compleja situación de Chile en el período que precede al conflicto antillano, lo que les permitió, la mayoría de las veces, ser reconocidos como legítimos combatientes por sus oficiales superiores y la tropa que comandaron.

Palabras Claves: americanismo chileno; solidaridad con Cuba; autopercepción de lo chileno; Independencia de Cuba.

Cómo Citar este artículo / Citation: López Muñoz, Ricardo, "Nacionalismo y americanismo entre los voluntarios chilenos en el Ejército Libertador de Cuba durante su segunda guerra de independencia (1895-1898)", Revista de Indias, LXXVIII/272 (Madrid, 2018): 211-235. https://doi.org/10.3989/revindias.2018.007

1 Agradezco los comentarios a la versión inicial de este artículo que me hicieran los profesores Joaquín Fernández Abara y Myriam Olguín. 


\section{INTRODUCCIÓN}

La segunda guerra de independencia de Cuba (1895-1898) ${ }^{2}$ convocó a un número relevante de extranjeros a participar en el bando de los insurrectos. Dominicanos, puertorriqueños, mexicanos, venezolanos, colombianos y españoles, entre otras nacionalidades, se integraron al Ejército Libertador como oficiales o simples soldados, combatiendo junto a los cubanos por la independencia de su patria. También participaron en esta guerra a lo menos dieciocho chilenos, que concurrieron a Cuba con el mismo objetivo. Fue un contingente modesto en número, pero expresivo de la simpatía y la solidaridad que en Chile despertó la causa cubana. Su presencia en la isla ha sido reseñada por una acotada historiografía divulgativa — en general bien documentada-, sobre todo de autores cubanos ${ }^{3}$. En ella se aportan datos acerca de su participación en la guerra y se destaca su entrega y sacrificio. En el presente artículo nos proponemos analizar cómo sus circunstancias y experiencias en Chile influyeron en su determinación de partir y en sus conductas en el escenario de la guerra. Todos ellos, antes de pensar en integrarse al Ejército Libertador cubano, formaban parte de una sociedad sujeta a importantes mutaciones sociales y políticas, y en donde se había decantado un singular nacionalismo, potenciado tras la Guerra del Pacífico.

En efecto, si bien a fines del siglo XIX la sociedad chilena estaba gobernada por una élite convencidísima quizá como nunca que su poder político, económico y social era incuestionable, el fin de siglo mostraba también la marcada presencia de nuevos actores sociales y políticos. Los sectores medios se habían expandido en número y calidad, y ocupaban nuevos espacios laborales en los servicios, en la burocracia estatal y en ciertas profesiones. Sus representantes intervenían cada vez más en los debates políticos del país. Asimismo, los sectores populares urbanos se encontraban en un creciente proceso de organización y también tendían a manifestarse de manera autóno-

2 Entre 1868 y 1878 Cuba vivió un primer proceso de independencia, conocido como La Guerra de los Diez Años. Rivalidades entre los independentistas, más el desgaste de una década de combates, determinó que un sector relevante de los insurrectos negociaran un pacto con las autoridades españolas, el 10 de febrero de 1878, con el que se dio término a la guerra, sin que alcanzara sus objetivos. Para un análisis de este proceso ver a Aguirre, 1978. Torres-Cuevas y Loyola, 2002: 280-285.

3 Los historiadores cubanos que han investigado la presencia de los chilenos en la guerra de independencia de 1895 son Armas, 1984: 147-168. González Barrios, 2007: 67-121. Mesa García, 2011: 54-71. También historiadores chilenos han reseñado el paso de sus compatriotas por el Ejército Libertador cubano. Es el caso de López Muñoz, 1994: 91-100. Arancibia Clavel, 2009: 86-103. 
ma dentro de los debates públicos. Todos tenían viva en sus retinas la guerra civil de 1891 que llevó al derrocamiento del presidente José Manuel Balmaceda. La mayor parte de la élite había sido la vencedora de esa guerra. Los derrotados se encontraban en un segmento minoritario de ella, junto a parte de los sectores medios, del Ejército, y del bajo pueblo.

Por otra parte, en el período se ha consolidado un relato identitario acerca de la nación que impregna, con distintas intensidades, al conjunto de la sociedad. Este relato tiene entre sus soportes las ideas de que el país constituye una excepción de orden dentro de América Latina por su relativa estabilidad política (no obstante la reciente guerra civil); que su cultura es de raigambre europea y por lo tanto es una nación «civilizada» — para algunos la más «civilizada» de América Latina-; y que las experiencias de las guerras de independencia, contra la Confederación Peruano-boliviana, y la del Pacífico, han puesto en evidencia que sus habitantes constituyen una estirpe de guerreros victoriosos ${ }^{4}$. Por supuesto, los distintos segmentos que conforman la sociedad finisecular interpretan este discurso desde sus heterogéneas experiencias, y desde las profundas asimetrías económicas, sociales, culturales y políticas que los diferencian.

Es en este contexto que llega al país la noticia de la nueva insurrección cubana, la cual despertará amplias simpatías, pero sobre todo entre los sectores populares urbanos, en un limitado grupo de sectores medios ilustrados, y en parte del Ejército - de donde procederá la mayoría de los voluntarios que concurran a Cuba- Al contrario, la élite se mostrará indiferente y aún hostil ante la causa de los cubanos. El gobierno no demorará en declarar su neutralidad ante el conflicto y en varias ocasiones obstaculizará las manifestaciones públicas de apoyo a los insurrectos. El enviado del Partido Revolucionario Cubano 5 (PRC), Arístides Agüero, quien llega a Chile el 6 de octubre de 1895, y que será - junto con el puertorriqueño Eugenio María de Hostos, residente en el país por entonces - el principal reclutador de chilenos dispuestos a viajar a Cuba, rápidamente se dará cuenta de las encontradas opiniones que genera en la sociedad chilena la insurrección anti-

4 Varios son los historiadores que han estudiado las características de este nacionalismo de fin de siglo. Tenemos presente a San Francisco, 2009, vol. I: 55-84. Cid, 2011: 163-178. Subercaseaux, 2011, vol. II: 211-221. Mc Evoy, 2007: 540-550; 2011: 89-156.

5 El Partido Revolucionario Cubano, fundado en 1892, fue organizado y dirigido por José Martí con el objetivo de reunir a la mayoría de los independentistas y organizar y encabezar la nueva guerra de independencia. A partir de 1895 asumió la tarea de desarrollar las relaciones diplomáticas de la insurrección. Al respecto ver Cordoví, 2014: 403-405. 
1lana. Así se lo informa al Delegado del PRC, Tomás Estrada Palma ${ }^{6}$, el 16 de octubre de 1895:

... los demócratas, radicales, obreros y estudiantes están con nosotros, pero los conservadores y clericales nos hacen guerra sorda: razones.

1. $\quad$ Creen representa España el catolicismo y defiéndenla con calor influenciados por el clero español que aquí es numeroso e influyente, (...)

2. ${ }^{\circ}$ Hay mucho orgullo de clase y sangre, todos quieren ser herederos directos de los héroes iberos de la conquista y edad media: se enorgullecen de la raza, de la Madre patria, etc.

3. ${ }^{\circ}$ El ministro español está relacionado muy bien, es santurrón, intrigante, los halaga defendiendo su genealogía española, etc., temen disgustarse con él y que les descubra los títulos de pega que aquí presentan si no todos, la mayor parte ${ }^{7}$.

Bajo estas circunstancias es que un grupo importante de chilenos manifestará - a veces públicamente, a través de la prensa - su voluntad de integrarse al Ejército Libertador cubano. De entre ellos, un reducido contingente así lo hará, combatiendo en la isla por su independencia. Unos y otros apelaron a lo que consideraban «el cumplimiento de un deber americano» ${ }^{8}$. Sin embargo, aquellos que finalmente desembarcaron en Cuba, enfrentados a su nueva realidad, debieron recurrir a algunos de los componentes del relato identitario nacionalista dominante en su país para así integrarse con éxito a una guerra que les había resultado altamente empática pero que ahora les resultaba extraña para sus percepciones de mundo. El análisis de sus testimonios y registros en fuentes documentales, periódicas y bibliográficas — cubanas y chilenas - nos permite plantearnos la hipótesis de que su adhesión al independentismo cubano pasó por la resignificación que hicieron de dos de los soportes de este relato identitario nacionalista: la condición "civilizada» y el carácter «guerrero» de sus habitantes. Desde la percepción de que estos «valores» les eran

6 La autoridad máxima del PRC era el «delegado», cargo que ocupó Martí hasta su muerte el 19 de mayo de 1895. Desde entonces el Delegado fue Tomás Estrada Palma. Ver al respecto Torres-Cuevas y Loyola, 2002: 337-341.

7 "De Arístides Agüero a Tomás Estrada Palma, Santiago, 16 de octubre de 1895", Correspondecia Diplomática..., 1944, vol. II: 27-28.

8 En esos términos se expresa Arturo Villaruel en la carta que dirige a Arístides Agüero desde Santiago, el 29 de enero de 1897, solicitándole su traslado a Cuba. Reproducida por González Barrios, 2007: 90-91. Otro voluntario, Carlos Dublé, ya en la isla, dirá que se incorporó a las filas insurrectas porque «la libertad de Cuba es el complemento de la emancipación americana». Dublé, 1900: 223. 
propios e inherentes, se pusieron al servicio de una causa que entendieron como tremendamente justa y que hicieron suya, recurriendo a lo que consideraban su impronta nacional. Como veremos, con su comportamiento dieron significado a un americanismo que se sustentaba sobre todo en sus experiencias y sentidos de pertenencia, donde la «patria» civilizada y guerrera, como algo inscrito en la piel y en la conciencia de cada uno de ellos, sería la razón de su valor, entrega y sacrificio, aún en una tierra lejana.

\section{DE LAS CONDICIONES PARA SER UN INSURRECTO CHILENO}

La mayoría de los chilenos que manifestaron su deseo de partir a Cuba y aquellos que finalmente lo lograron, eran militares de carrera, pero sólo algunos de ellos estaban en servicio activo dentro del Ejército hacia 1895. Ello se explica porque desde 1886 este cuerpo armado se encontraba en un proceso de modernización que involucraba - entre otros aspectos - una reducción importante de la dotación de oficiales subalternos. No obstante, bajo el gobierno que se constituyó terminada la Guerra Civil de 1891, esta reorganización adquirió características políticas. Teniendo presente que buena parte del Ejército se había mostrado leal al derrocado presidente Balmaceda, bajo la cobertura de la modernización fueron también dados de baja aquellos oficiales que habían mostrado antecedentes de adhesión a la causa balmacedista ${ }^{9}$. Como quiera que fuera, todo ello generó un contingente de oficiales desempleados de los que saldría una parte de quienes se ofrecieron como voluntarios para concurrir a Cuba.

La mayoría de estos ex militares estaban marcados por la guerra civil y sus consecuencias. El voluntario y ex capitán José Agustín Sanhueza -que en la guerra civil combatió del bando de Balmaceda - declaraba ser adherente del partido Liberal Democrático ${ }^{10}$ y ser «servidor del Ejército leal y defensor, por lo tanto, de los intereses del pueblo»» ${ }^{11}$ Otro voluntario, el ex teniente Arturo Lara, era caracterizado en las crónicas del periódico El Americano como un decidido liberal balmacedista:

\footnotetext{
9 Respecto a la reorganización del Ejército a partir de 1891, ver Historia del Ejército de Chile, 1985, vol. VII: 175-188.

10 El Partido Liberal Democrático, fundado en 1893, agrupaba a los antiguos partidarios del Presidente Balmaceda.

11 De una carta de José A. Sanhueza a Estrada Palma, fechada en Panquehue, el 11 de marzo de 1897, reproducida por González, 2007: 91-93.
} 
El joven Lara, tiene a pesar de sus cortos años, una brillante hoja de servicios por los principios de la libertad. (...) Se batió heroicamente en Placilla en 1891, en las filas del batallón Angol, bajo las órdenes de Jefes caracterizados del antiguo Ejército de la República. (...) el joven Arturo cumplió noblemente su deber de soldado, no habiendo la derrota amenguado su amor a la libertad. (...) Abonan la rectitud y la abnegación del joven Lara, su lealtad a la causa liberal-democrática, por la cual se batió en los combates y en cuyas filas ha permanecido fiel en la derrota y en el infortunio ${ }^{12}$.

Por otra parte, el ex subteniente Carlos Buonocore expresaba, en una entrevista de prensa realizada después de que regresara de Cuba, adhesiones políticas que iban más allá del conflicto del 91: «Terminada la campaña presidencial en favor de don Federico Errázuriz, del que fui gran admirador, creí, ¡qué triste engaño!, que en este país sentaría sus reales la felicidad, y contento me embarqué» ${ }^{13}$.

También hubo no pocos militares en activo que se ofrecieron para pelear por la independencia de Cuba. En general la causa antillana resultó empática para los miembros del Ejército y de la Armada de Chile. De hecho, recién iniciada la guerra en la isla, algunos de ellos participaron en actos públicos de solidaridad con los insurrectos, lo que determinó que el gobierno prohibiera su presencia en esas manifestaciones. Incluso llegó a ordenar al Comandante General de Armas de Santiago, general Novoa, que dictase orden de arresto para los oficiales del Ejército y los cadetes de la Escuela Naval que concurrieron a un meeting estudiantil de apoyo a los cubanos, el 14 de julio de $1895^{14}$. Asimismo, en algunas ocasiones oficiales del Ejército y la Armada - violando las prohibiciones establecidas por el gobierno - invitaron a Arístides Agüero a sus cuarteles. Durante su visita a la ciudad de Talca, concurrió al cuartel del Batallón Antofagasta 8. ${ }^{\circ}$ de línea, "siendo objeto de singulares manifestaciones de parte de los jefes y oficiales existentes» ${ }^{15}$. También el 12 de noviembre de 1896, encontrándose en el puerto de Coquimbo, fue recibido a bordo del blindado «Capitán Prat»" ${ }^{16}$. También en la correspondencia de Agüero y en la de Hostos resulta evidente que ambos sostuvieron contactos con altos mandos de las dos ramas de las Fuerzas Armadas y que sus jefatu-

12 El Americano, Santiago de Chile, 21 de noviembre de 1895.

13 Entrevista a Carlos Buonocore, publicada en La Tarde, Santiago de Chile, 19 de julio de 1898. Federico Errázuriz Echaurren fue presidente de Chile entre 1896 y 1901. Su elección fue producto de una alianza entre sectores liberales y conservadores.

${ }_{14}$ La Lei, Santiago de Chile, 15 de julio de 1895; El Noticiero Español, Santiago de Chile, 18 de julio de 1895 .

15 La Libertad, Talca, 6 de noviembre de 1895.

16 La Reforma, La Serena, 13 de julio de 1896. 
ras en algunos casos recomendaron o avalaron a los voluntarios que provenían de sus filas.

Pero una cosa era ofrecerse como voluntario y otra realizar efectivamente el viaje a Cuba. «Diariamente rechazo proposiciones de enganche, desvanezco ilusiones de niños» le escribe Agüero al Delegado del PRC ${ }^{17}$. Son numerosas las solicitudes que el cubano recibe de personas de distinta condición social que manifiestan su deseo de concurrir a la isla. Por ejemplo, el 13 de febrero de 1896 le escribe desde Coquimbo Manuel Atria diciéndole: «Yo con lo único que puedo ayudarle es con mis brazos. (...) espero (...) que Ud. se dignará contestarme dándome los datos necesarios para trasladarme a mi patria chica» ${ }^{18}$. También lo hacen Julio Baterrica y Feliciano Torres, el 17 de febrero, señalándole: "Yo señor, otro compañero y talvez tres más, que la pobreza no nos permite ayudar a esa segunda patria con el contingente del dinero, $(. .$.$) deseamos que de alguna manera se nos trasporte allá» { }^{19}$. Ninguno de estos voluntarios pudo viajar a Cuba. El representante del PRC no contaba con recursos para financiar su traslado.

Tanto Agüero como Hostos sólo avalaron a quienes podían financiar total o parcialmente su viaje a la isla. Y quienes así podían hacerlo, necesariamente pertenecían a los sectores medios chilenos, cuando no a la misma élite. En las cartas que los recomiendan ante el Delegado del PRC o ante ciertas figuras prominentes del independentismo, los reclutadores antillanos destacarán ciertas virtudes propias de la condición social de los voluntarios. Así, Paulino Ahumada era presentado como «hijo de familia bien situada, (...) afortunado, (...) bien quisto en la buena sociedad» ${ }^{20}$, Arturo Lara era «de distinguida familia» ${ }^{21}$, Darío Montt «es un muchacho decente» ${ }^{22}$, Manuel Marcoleta y Federico Gabler eran «inteligentes e instruidos» ${ }^{23}$, Amaro Marambio «es de

17 "Carta de Arístides Agüero a Tomás Estrada Palma, Santiago, 23 de octubre de 1895", Correspondecia Diplomática..., 1944, vol. II: 32.

18 Carta de Manuel Atria a Arístides Agüero, Coquimbo, 13 de febrero de 1896, Biblioteca Nacional José Martí, La Habana (BNJM), Colección Cubana, Fondo de Manuscritos, Colección de Manuscritos de Rafael Montoro, vol. LIV, doc. 29.

19 Carta de Julio Baterrica y Feliciano Torres a Arístides Agüero, Coquimbo, 17 de febrero de 1896, BNJM, Colección Cubana, Fondo de Manuscritos, Colección de Manuscritos de Rafael Montoro, vol. LIV, doc. 30.

20 Carta de Eugenio María de Hostos a Gonzalo de Quesada, Santiago, 29 de julio de 1895, reproducida en Hostos, 1939, vol. IV: 141.

21 "Carta de Arístides Agüero a Tomás Estrada Palma, Chillán, 18 de noviembre de 1895", Correspondecia Diplomática..., 1944, vol. II, 34.

22 Citado por González Barrios, 2007: 82.

23 "Carta de Arístides Agüero a Tomás Estrada Palma, Lima, 13 de enero de 1897”, Correspondecia Diplomática ..., 1944, vol. II: 81. 
familia acomodada y de buenas relaciones» ${ }^{24}$. Entre los voluntarios, los cubanos se encontraron con individuos «civilizados», tal como ellos se percibían a si mismos, y dentro de una sociedad donde el relato identiario nacionalista dominante hacía hincapié en dicha cualidad para un segmento de ella, y donde quienes más la ostentaban eran las personas calificadas como «decentes», de «buena familia», o «caballeros». Casi todos los voluntarios se adscribían a esos términos.

Ciertamente, quizá fue inevitable que el estatus social de los voluntarios interviniera como requisito para la comunicación entre personas que no se conocían. Antes del inicio de la guerra, chilenos y cubanos carecían de contactos regulares, y para relacionarse los primeros requirieron presentar trazas de una adscripción que no podía reducirse a su simpatía por la causa cubana, sus pergaminos como militares de experiencia o su disposición para financiar el viaje. En su interlocución con los reclutadores debieron dar cuenta también de una pertenencia social y cultural que les permitiera manejar los mismos códigos de lenguaje y de sociabilidad de Agüero, Hostos y de otros cubanos que eventualmente los acogerían en su tránsito a las Antillas, todos ilustrados, miembros de los sectores medios de la isla ${ }^{25}$. Por este medio podían reconocerse, saber quien era el otro, y asegurar la seriedad de unos y el compromiso ante la causa cubana de otros. Pero más allá de esta necesidad, su condición social intervino como una señal de pertenencia a una comunidad «civilizada», similar y valorada entre quienes acogieron su deseo de partir a Cuba.

Al mismo tiempo, en su estancia en Chile, los reclutadores cubanos no demoraron en asumir como una verdad otro de los componentes del relato nacionalista que marcaba a la sociedad chilena de entonces, y que resultaba funcional a las expectativas que tenían de los futuros combatientes: la cualidad de sus habitantes, y especialmente de los militares, de ser guerreros probados; algo que en cualquier caso no le resultó evidente a Estrada Palma, que a inicios de 1897 le solicitó a Agüero expresamente que no contribuyera a enviar más chilenos a Cuba, pues a su juicio tenían «... un concepto erróneo de nuestra guerra; la creen ajustada al patrón de una guerra regular, (...) no calculan las estrecheces y privaciones y fatigas a que allá se está sujeto; (...) tan

24 "Carta de Arístides Agüero a Tomás Estrada Palma [sin fecha / sin localización]", Correspondecia Diplomática..., vol II: 96.

25 En el período posterior a la Guerra de los Diez Años los sectores medios cubanos tenderán a crecer, tal como acontece en general en América Latina. A fines del siglo XIX un segmento importante de este grupo social se integrará al Partido Revolucionario Cubano, participando activamente en la guerra independentista de 1895. Al respecto ver Ibarra, 1980: 130-137. Torres-Cuevas y Loyola, 2002: 304-309. Zanetti, 2013: 185. 
pronto como dan con la dura realidad la decepción es muy dolorosa y a menudo nos convierte en enemigos a aquellos en quienes creíamos tener unos aliados» ${ }^{26}$. Pero a esa altura, Agüero estaba convencidísimo de las inequívocas singularidades marciales de los chilenos, y con esta convicción respondió a los requerimientos del Delegado:

... mis chilenos son hombres aguerridos y excelentes instructores - cosa muy necesaria para nosotros - no sólo de guerra clásica, etc., sino de guerrillas y montoneras; han sido también ejercitados en guerra muy parecida a la nuestra en la campaña del 91. Ellos saben lo que es hambre, sed y desnudez pues en su mismo país la soportaron. (...) Estos oficiales pertenecen a un ejército valiente, sufrido y sumamente disciplinado; es decir, que obedecen sin discutir, avanzan a la muerte serenos y tienen un amor propio de valor y sacrificio extraordinario. (...) yo respondo que no darán motivo de queja los chilenos enviados por mí. (...) En Chile hay un entusiasmo grandísimo por Cuba y si más cerca estuviera tendríamos miles de chilenos en campaña y sin costarnos un centavo ${ }^{27}$.

Como quiera que fuera, las virtudes presentadas por los chilenos para obtener el aval que les permitiría combatir en Cuba, resultaron ser parte de aquellas que estructuraban el nacionalismo dominante en el país y de las cuales se sentían impregnados. Y los reclutadores cubanos las ratificaron al destacar, en función de sus objetivos, que procedían de un país civilizado y con una vocación guerrera indiscutible.

\section{ENTRE LA ILUSIÓN, EL RECONOCIMIENTO Y LA LEGITIMIDAD}

Los voluntarios que finalmente desembarcaron en $\mathrm{Cuba}^{28}$ colisionaron con una realidad hasta entonces sólo imaginada. Antes de partir, Carlos Dublé asociaba la guerra a «La poesía, esa vida aventurera y alegre de las montoneras ${ }^{29}$. Carlos Buonocore dirá que «... tenía por la causa cubana, una especie de idolatría. Deliraba por encontrarme en las filas de esos valientes que

26 "Carta de Tomás Estrada Palma a Arístides Agüero, Nueva York, 9 de enero de 1897”, Correspondecia Diplomática..., 1944, vol. I: 112.

27 "Carta de Arístides Agüero a Tomás Estrada Palma, Quito, 18 de marzo de 1897", Correspondecia Diplomática..., vol. II: 91.

${ }_{28}$ Los chilenos que efectivamente pudieron emprender el viaje hacia las Antillas lo hicieron realizando un trayecto que pasaba generalmente por El Callao, Panamá, Nueva York, y de allí a alguna ciudad de La Florida. Sólo entonces, — quienes lograron recorrer hasta el final este largo camino- eran embarcados en las expediciones destinadas a Cuba.

29 Dublé, 1900: 50-51. 
palmo a palmo se disputan el suelo que les pertenece» ${ }^{30}$. Sin embargo, la realidad disolvería toda perspectiva romántica. Recién llegados, se enfrentaron con los horrores de la guerra, y con sus principales víctimas, la población civil. Manuel Marcoleta relata su conmoción ante el primer contacto con ella:

... permanecimos unas cuantas horas, cerca de una casita de campo, llamada aquí Bohío, (...) Ahí había una pobre familia, guajira o campesina como nosotros llamamos. ¡Pobre jente!, ¡da pena verla en el estado en que se encuentra! Es un estado de semi desnudez i de color cadavérico; efecto de la debilidad por la miseria i escasez que pasan. (...) Ver aquellas pobres jentes daba horror. Los niños desnudos por falta de ropa, porque hacía días que había pasado una columna española i les había quemado la casita en que vivían i apenas habían tenido tiempo para escapar. ¡Casi todos enfermos i a medio vestir! Es necesario ver esto para formarse una idea de la inclemencia española ${ }^{31}$.

Asimismo, para militares formados en un ejército regular, y aún para los pocos civiles cuya percepción del ejército de su país era la de una institución formal y organizada, el anhelado encuentro con el Ejército Libertador cubano dejó en ellos sensaciones encontradas. Así le aconteció a Dublé, cuando ingresa a las tropas del Regimiento Habana: «¡cómo pueden ser éstos, nos dijimos, los que pelean con un ejército como el español! (...) Aquellos pobres, amarillos, enflaquecidos, con la barba crecida y los ojos hundidos, nos miraban con envidiosa curiosidad» ${ }^{32}$. Algo similar le sucedió a Marcoleta: «Supóngase, mi amigo, que la mayor parte de esa jente, negros i blancos, están casi desnudos; muchos como nuestro padre Adán, con una hoja de parra, i otros sin ella. I toda esa jente tan contenta como usted no puede tener idea; ¡hasta oficiales a pie pelado! por no haber ropa ni calzado» ${ }^{33}$. La misma impresión tiene Buonocore: «... encontramos en un lugarcito denominado Bello a cien soldados negros, completamente desnudos. Era de ver el espectáculo

30 Entrevista a Carlos Buonocore, publicada en La Tarde, Santiago de Chile, 19 de julio de 1898.

31 De una carta de Manuel Marcoleta, fechada en Cuba Libre, Campamento La Pita, Habana, el 30 de mayo de 1897, publicada en el periódico La Lei, Santiago de Chile, 30 de septiembre de 1897. Varios fueron los extranjeros que como primeras impresiones de la guerra expresaron testimonios similares al de Marcoleta. Francisco Gómez Toro, hijo del dominicano y General en Jefe del Ejército Libertador, Máximo Gómez, en la primera carta que envía a su familia después de desembarcar en Cuba, dice: «En los primeros días sentí en la guerra una especie de aturdimiento, viendo las crueldades de ella. (...) Vi tantas mujeres marchado en la columna con sus hijos muriéndose», citado por Zamora, 1988: 90.

32 Dublé, 1900: 50-51.

33 De una carta de Manuel Marcoleta, fechada el 30 de mayo de 1897, publicada en La lei, Santiago de Chile, 3 de agosto de 1897. 
que ofrecía ese pequeño ejército cubano. Los más elegantes llevaban como única prenda del uniforme una correa en la cintura donde estaba sujeto el machete ${ }^{34}$.

Sus impresiones son las de individuos que de súbito se enfrentan con una realidad impensable de acuerdo a como hasta entonces habían percibido las guerras y sus actores. Las que conocen son la Guerra del Pacífico y la Guerra Civil de 1891. En ambas participó el ejército regular de su país, con frentes de batalla definidos, con logísticas quizá precarias pero existentes, dentro de entornos geográficos para muchos no muy distintos de los que conocían antes de cada conflicto. Sin embargo, la guerra cubana no tenía esas características. Si bien el Ejército Libertador contaba con una estructura de mando y una organización, la mayor parte de la tropa estaba conformaba por campesinos que voluntariamente se habían integrado a las fuerzas insurrectas, en razón de su patriotismo o de sus circunstancias de extrema pobreza, sin antecedentes de una formación militar previa que no fuese, en el caso de los de más edad, el haber participado en la Guerra de los Diez Años. A ello se sumaba que, en general, el ejército insurrecto operaba en condiciones extremadamente adversas dado el impresionante número de tropas peninsulares rápidamente desplazadas a la isla al iniciarse el alzamiento. La proporción a fines de 1895 era de 103.761 soldados metropolitanos ${ }^{35}$ contra aproximadamente 40.000 cubanos en armas, lo que determinaba que las fuerzas patriotas estuviesen en constante movimiento, bajo la forma de columnas que realizaban marchas y contra marchas conforme lo requería una correlación de fuerzas militares muy variable entre ambos bandos ${ }^{36}$.

Por otra parte, una vez en suelo cubano los voluntarios se encontraron con que las recomendaciones que les había permitido llegar hasta allí ya no les servían como aval para su inserción entre los insurrectos. En el periplo que habían realizado para llegar a la isla éstas habían operado como una suerte de patentes de identidad social compartida ante quienes los acogieron y encaminaron al campo de batalla. Ellas garantizaban una pertenencia social y una certificación de su sincera voluntad de ir a pelear a Cuba, que los hacía reconocibles y empáticos con sus pares antillanos, que como tales los recibían. En

34 Entrevista a Carlos Buonocore, publicada en La Tarde, Santiago de Chile, 19 de julio de 1898.

35 Se calcula que durante la segunda guerra de independencia cubana unos 220.000 españoles fueron enviados a combatir contra los insurrectos, de los cuales casi la mitad llegó en el primer año de la guerra. Al respecto ver Sánchez Abadía, 2001: 120-121.

36 Respecto a las características militares de la guerra del 95, ver a Torres-Cuevas y Loyola, 2002: 365-386. En cuanto a las razones por las que se integran los campesinos cubanos a las tropas del Ejército Libertador ver a Ibarra, 2003: 35-53. 
los testimonios que describen total o parcialmente el viaje a Cuba subyace esta perspectiva por la cual los chilenos asumen estar entre iguales, social y culturalmente, ya sea en el Callao, en Panamá, en Nueva York, en Tampa, e incluso en el barco que finalmente los llevará a la isla. Marcoleta, a punto de embarcarse, señala que su expedición «Llevará (...) ciento cincuenta decididos jóvenes de la mejor sociedad cubana. Entre los espedicionarios figura el Ministro de la Guerra, jeneral Roloff, i algunas otras personalidades». Además indica que «Con las buenas recomendaciones que traíamos del delegado cubano señor Arístides Agüero, para su respetable hermana i otros caballeros, entre los cuales se cuenta el presidente de la delegación de Cuba, fuimos mui bien recibidos,... (...) ya no admiten más jente para Cuba; pero como nosotros traíamos mui buenas cartas de recomendaciones del delegado señor Agüero, nos aceptaron gustosos $\rangle^{37}$.

Empero, estas recomendaciones perderán su relevancia una vez que se encuentren en Cuba, no obstante que algunos de sus portadores insistieron por algún tiempo en respaldarse en ellas para combatir donde ellos querían. Carlos Dublé testimonia que su situación fue al principio muy difícil

\begin{abstract}
... a causa de que otros chilenos que desembarcaron en esta provincia antes que yo, no servían con gusto, no aceptaban ningún puesto porque deseaban servir a las órdenes del jeneral Calisto García, que operaba en Oriente, i para quién traían recomendaciones. (...) Sufrí bastante al principio, a causa de lo que he dicho, de que desconfiaban de nosotros por el deseo que manifestaron algunos de ir a servir a otras provincias $^{38}$.
\end{abstract}

Como todos los que llegaban del extranjero, los chilenos debieron adaptarse a un país donde el orden social se había alterado por efecto del conflicto en que se encontraba sumergido. No es que las marcadas diferencias sociales características del fin de siglo cubano hubiesen desaparecido, pero la guerra había a lo menos cambiado la relativa estabilidad de un orden social jerarquizado, compeliendo a las élites, a los sectores medios y al bajo pueblo integrados al Ejército Libertador, a reorganizar sus relaciones de subordinación en función de un conflicto que involucraba liderazgos y conductas que en general escapaban a las existentes antes de la guerra, y donde todos los

37 De una carta de Manuel Marcoleta, fechada en Nueva York, el 3 de febrero de 1897, publicada en La lei, Santiago de Chile, 19 de mayo de 1897.

38 De una carta de Carlos Dublé a Diego Dublé Almeida, fechada en Matanzas, Campamento de Yucayó, el 28 de septiembre de 1898, publicada en La Lei, Santiago de Chile, 17 de diciembre de 1898. 
días se arriesgaba la vida, sin importar el grado o estatus social que se poseyera.

En estas condiciones, más allá de cualquier recomendación, lo que se puso en juego entre los voluntarios chilenos fue su capacidad de adaptación. Conforme a los testimonios con que contamos, sólo dos de ellos - Carlos Buonocore y Luis Ahumada - no pudieron asimilar sus nuevas circunstancias, pasándose — según el testimonio de Dublé— al bando español ${ }^{39}$. Posiblemente sobre ellos primó la dificultad de romper con los moldes del ordenamiento social del que formaban parte en Chile. Buonocore, tras regresar al país, evaluaba así su experiencia en la guerra: «Es un tremendo engaño (...) creer que los cubanos tienen plena conciencia de su situación. Allí la masa popular pelea porque si, sin organización alguna y llevados como carneros por ciertos jefes. (...) Las tropas no tienen ni armas, ni municiones ni uniformes $\rangle^{40}$. Como quiera que fuera, su testimonio refleja la dificultad de comprensión y adaptación que todos los voluntarios enfrentaron ante el desconocido y romantizado escenario de la guerra de independencia cubana. Ante él debieron esforzarse por comprender su nueva realidad y adecuarse a ella. Como veremos, la mayoría lo logró. Marcoleta dirá: «Yo pensaba (...) ir donde está el jeneral Gómez, pero es mui difícil i aquí me han propuesto que me quede como segundo jefe de infantería, con el grado de comandante, lo que he aceptado sin vacilar» ${ }^{41}$.

Rotas las ilusiones y expectativas iniciales, la integración de los voluntarios chilenos al Ejército Libertador pasó por demostrar ante los cubanos que interactuaban con ellos su honesta y efectiva capacidad para sumarse a la guerra. Cabe suponer que no debió ser tarea fácil. Más allá de cualquier recomendación, nadie los conocía en un terreno donde el valor, las dotes de mando, y la resistencia ante las dificultades eran capacidades constantemente puestas a prueba. En varios casos, los ascensos de los chilenos - a los cuales se les respetó el grado que habían alcanzado en el ejército de su país- fue un indicador del reconocimiento que adquirieron como insurrectos y de la legitimidad que lograron como oficiales al mando de tropas. Por ejemplo, el

39 De una carta de Carlos Dublé a Diego Dublé Almeida, fechada el 1. e mayo de 1898, publicada parcialmente en La Lei, Santiago de Chile, 17 de diciembre de 1898. Buonocore declarará en la entrevista que publica $L a$ Tarde, el 19 de julio de 1898, que fueron tomados prisioneros por fuerzas españolas en un combate.

40 Entrevista a Carlos Buonocore, publicada en La Tarde, Santiago de Chile, 19 de julio de 1898.

41 De una carta de Manuel Marcoleta, fechada en Cuba Libre, Habana, Campamento La Pita, el 3 de mayo de 1897, publicada en La lei, Santiago de Chile, 4 de septiembre de 1897. 
teniente Arturo Lara muere en combate con el grado de teniente coroneli2; el teniente Federico Gabler fallece con el grado de capitán ${ }^{43}$; Ricardo Elizary, abogado, alcanza el grado de comandante, auditor de guerra ${ }^{44}$; el teniente coronel Temístocles Molina termina la guerra como coronel${ }^{45}$; el capitán Héctor Marcoleta muere como comandante de regimiento ${ }^{46}$; el «mecánico» Juan A. Brunet alcanza el grado de teniente ${ }^{47}$; Carlos Dublé, que se inicia en la guerra como simple soldado, la termina como teniente ${ }^{48}$. Finalmente, Pedro Vargas Sotomayor, teniente o capitán al momento de desembarcar en Cuba, muere como general de brigada ${ }^{49}$. Asimismo, en la prensa chilena que recoge las noticias y testimonios de los voluntarios en Cuba, en algunos casos se indican sus grados dentro del Ejército Libertador. Por ejemplo, Carlos Buonocore relata haberse encontrado con «Constantino Varas, otro chileno que con el grado de capitán buscaba la muerte en defensa de Cuba ${ }^{50}$. También se menciona al «mayor Martínez muerto valientemente en Taguasco (Villaclara) ${ }^{51}$; y se describe una de las acciones en donde habría participado el capitán Rubén Machuca, quien «se tomó en la batalla de Guantánamo dos piezas de artillería» ${ }^{52}$.

Si los chilenos alcanzaron puestos de confianza y responsabilidad en las filas de los insurrectos, ello sólo fue posible porque en los combates demostraron adaptación a las circunstancias de la guerra, coraje y capacidades de mando, que los legitimaron como combatientes ante sus superiores y las fuerzas que comandaron. Las fuentes cubanas registran solo a dos chilenos que no alcanzaron grados dentro del Ejército Libertador: Francisco Paneque y José Betancourt. Ambos sirven como soldados y sus oficios son definidos como «del campo» ${ }^{53}$.

42 González Barrios, 2007: 79.

43 Armas, 1984: 168.

44 Ibidem: 167.

45 Ibidem: 166.

46 Ibidem: 168.

47 Ibidem: 167.

48 Así lo indica la carta que su superior, el general Pedro Betancourt, le dirige a su padre, Diego Dublé Almeida, el 28 de septiembre de 1898, publicada en La Lei, Santiago de Chile, 17 de diciembre de 1898 .

49 Armas, 1984: 167.

50 Entrevista a Carlos Buonocore, publicada en La Tarde, Santiago de Chile, 19 de julio de 1898.

51 El Americano, Santiago de Chile, 22 de diciembre de 1895.

52 Ibidem, 14 de noviembre de 1895.

53 Armas, 1984: 166-167. Según el historiador González Barrios, es posible que residieran en Cuba al estallar la guerra y fueran de origen humilde. González, 2007: 100-101. 
También, de manera limitada, encontramos en fuentes chilenas y cubanas juicios acotados respecto a algunos voluntarios. Por ejemplo, al parecer Rubén Machuca es un combatiente altamente valorado entre los oficiales cubanos, si le creemos a la prensa chilena que indica que «mereció los aplausos del general Maceo» ${ }^{54}$. Por otra parte, según el testimonio de Carlos Dublé, su compatriota Arturo Lara «mandaba medio regimiento de infantería, y por su bueno se había conquistado el nombre de 'El león chileno'» ${ }^{55}$. El mismo Dublé tiene una conducta intachable durante la guerra, como se desprende de la carta que su superior le remite a su padre, recién terminado el conflicto.

El jeneral Pedro E. Betancourt tiene el honor de saludar al señor padre del teniente Carlos Dublé, e informarle que este oficial de nuestro ejército ha observado a nuestro lado una conducta digna de un soldado chileno-cubano. Terminada favorablemente nuestra contienda, el teniente Dublé podrá regresar a su patria llevando en una mano una corona de laurel i en la otra una rama de oliva. El teniente Dublé, uno de mis ayudantes de campo, tiene todo mi cariño i el de todos sus compañeros de armas ${ }^{56}$.

Por último el general de brigada Pedro Vargas Sotomayor, contaba con la más alta estimación de parte del general Antonio Maceo ${ }^{57}$. Vargas es el chileno que más alto grado alcanzó dentro del Ejercito Libertador. Como coronel, formó parte del Estado Mayor de Maceo en la columna invasora que llevó a los insurrectos del oriente al occidente de la isla. Por su notable trayectoria, fue ascendido a general de brigada por el propio Maceo el 21 de febrero de 1896. Un mes antes le había entregado el mando de una de las dos brigadas responsables de las operaciones en la provincia de Pinar del Río.

Así mismo, en algunos casos los testimonios de sus muertes también trasuntan valoraciones de sus conductas. Ésta a veces acontece en medio de los combates. Así le sucede a Arturo Lara. Su muerte es registrada por el general cubano Enrique Loynaz del Castillo, en la provincia de Matanzas, el 15 de junio de 1897: "Al recorrer hacia la izquierda otra vez nuestra línea —ya en silencio - tuve la dolorosa sorpresa de saber que había muerto el heroico teniente coronel Arturo Lara, noble oficial de Chile al servicio de nuestra li-

\footnotetext{
54 El Americano, Santiago de Chile, 14 de noviembre de 1895.

55 Dublé, 1900: 199.

56 Publicada en La Lei, Santiago de Chile, 17 de diciembre de 1898.

57 A decir del historiador y biógrafo de Antonio Maceo, José Luciano Franco, Vargas «... fue uno de los más brillantes oficiales de Maceo, valiente y de extraordinaria capacidad». Franco, 1989, vol. II: 51. A lo largo de los vols. II y III de esta obra es posible seguir la trayectoria de Vargas Sotomayor en la guerra de 1895.
} 
bertad $»^{58}$. También, ante la muerte de Vargas Sotomayor, acaecida en la provincia de Pinar del Río, en noviembre de 1896 - al parecer por efecto de una enfermedad que lo llevó a la demencia - el general cubano José Miró Argenter, Jefe del Estado Mayor de Antonio Maceo, dirá que «murió, (...) completamente loco, en las lomas de El Rubí. Era natural de Chile, teniente de la Armada de aquella república, hombre de mucho ánimo y probada lealtad» ${ }^{59}$.

Finalmente, los registros de las experiencias de los voluntarios en la guerra indican que la forma como percibían su condición de chilenos constituye un aliciente para el combate. Por ejemplo, según Dublé, «Conforme Lara oía nombrar a Chile, decía que no había cosa como esta tierra, y en prueba de ello andaba poniendo a cada rato su vida en un pelo. (...) Hermanos, - nos dijo en una ocasión (...) si volvemos a Chile, van a ponerse muy contentos por allá al saber que nos hemos portado bien» ${ }^{60}$. De alguna manera Arturo Lara imaginaba a su patria como una comunidad que le exigía una conducta propia de los sujetos que la conformaban: la de ser un guerrero valiente. Esta relación entre identidad nacional y vocación guerrera Lara la hará presente en los combates en que participa. El chileno fue conocido «porque al cargar el machete siempre gritaba ¡viva Chile! en vez de ¡viva Cuba!» ${ }^{61}$

De hecho, aún entre chilenos que no combaten, pero que observan de cerca las acciones de sus compatriotas integrados al Ejército Libertador, la «patria» está muy presente como una distinción que determina sus conductas. Uno de ellos es P. F. Desmoisnes, un comerciante que residía en La Habana. En su correspondencia con Chile señala: «El incansable Sotomayor (el rotito chileno) ha sido ascendido a jeneral de brigada. ¿Qué le parece al paisano? Felicíteme en mi nombre i de demás chilenos que habemos aquí a los colchagüinos, pues he sabido que Sotomayor es de San Fernando» ${ }^{62}$. Lo mismo hace respecto a Arturo Lara y su desembarco en Cuba: «Aquí se publicó los nombres de los que acompañaban a García i entre ellos veo el nombre de Lara, (chileno) supongo que sea de los Lara de Santiago. - ya con este hai mas de 120 paisanos en el ejército patriota- ¡Bien por Chile!» ${ }^{63}$ Aunque Desmoisnes

58 Citado por González Barrios, 2007: 79.

59 Ibidem: 117.

60 Dublé, 1900: 199.

${ }^{61}$ Conforme a una carta de Dublé del 28 de septiembre de 1898 publicada en La lei, Santiago de Chile, 17 de diciembre de 1898.

62 De una carta de P. F. Desmoisnes, fechada en La Habana, el 24 de marzo de 1896, publicada en La Lei, Santiago de Chile, 5 de mayo de 1896.

63 De una carta sin firma, pero a todas luces remitida por P. F. Desmoisnes, fechada en La Habana, el 12 de abril de 1896, publicada en La Lei, Santiago de Chile, 21 de mayo de 1896. 
llega a imaginar a su país contribuyendo con la causa cubana con un contingente cuyo número estaba lejos de la realidad, sus apreciaciones trasuntan un orgullo donde lo central es que en una guerra con la cual simpatiza, sus compatriotas demuestran una bravura y entrega que reflejan las virtudes explícitas de su patria.

Una perspectiva similar tiene Carlos Dublé a la hora de valorar la conducta de sus compatriotas: «... los que más se han distinguido i más alto han colocado el nombre de chilenos han sido Arturo Lara y Sotomayor, (...) También fueron mui queridos i mucho se distinguieron en los combates los infortunados Gabler i Marcoleta ${ }^{64}$. En su perspectiva, todos han sido genuinos representantes de Chile, y como tales, lo han hecho como guerreros reconocidos (en el fondo, ratificados) por sus pares cubanos.

Esta percepción de que frente a las exigencias de la guerra era necesario conducirse dentro de un canon ajustado a la manera como es comprendida la identidad nacional en el contexto de Cuba es incluso asumida por Diego Dublé Almeida, padre de Carlos Dublé. Éste le escribe a su hijo demandándole lo que considera la conducta propia de un chileno: ser buen soldado y un caballero. Ello se desprende de la respuesta que Dublé le remite el 28 de septiembre de 1898: "Ayer he tenido el gusto de recibir por primera vez carta de Ud. de fecha 5 de marzo. (...) Su carta, llena de nobles consejos i de cariño, me tiene muy contento. Puede Ud. estar seguro i satisfecho; he cumplido con los deberes de caballero i de soldado que Ud. me aconseja, i que yo mismo me impusiera» ${ }^{65}$. Y para confirmarlo estaba la opinión de su jefe insurrecto, que también le escribe a Dublé Almeida ratificándole que su hijo había tenido en la guerra «una conducta digna de un soldado chileno-cubano».

\section{CONCLuSIONES}

Ya sea por los grados que alcanzaron, o por los reconocimientos que obtuvieron, con su conducta la mayoría de los chilenos insurrectos compensaron con creces las aprensiones que inicialmente generaron entre los cubanos que los acogieron en el terreno de operaciones, aprensiones a veces justificadas por la dificultad que algunos mostraron para comprender la realidad de la guerra y adaptarse a ella. Esta adaptación involucró la readecuación de los

64 De una carta de Carlos Dublé a Diego Dublé Almeida, fechada en Matanzas, Campamento de Yucayó, el 28 de septiembre de 1898, publicada en La Lei, Santiago de Chile, 17 de diciembre de 1898 .

65 Idem. 
patrones de conducta propios de la sociedad de la que provenían; jerarquizada, ordenada, y donde las formas de relacionamientos entre los grupos sociales estaban altamente normadas e incluso definidas por términos precisos. En su nueva realidad, los voluntarios debieron adecuar sus prácticas y normas sociales a las de un vasto conglomerado de individuos entre los cuales, si bien había diferencias, por las circunstancias de la guerra estaban compelidos a interactuar en función de una causa cuyo horizonte los hermanaba, y donde el camino para alcanzarlo les demandaba formas de cooperación distintas a un orden de paz, y donde todos enfrentaban a un enemigo que no distinguía diferencias jerárquicas a la hora de combatirlo. Por lo tanto, solo resignificando a lo menos una parte de sus prácticas y experiencias previas, los voluntarios podían estar en condiciones de asumir como propios nuevos patrones de conducta y en consecuencia aportar con sus saberes, liderazgo y coraje en una guerra que, al menos al inicio, les fue inevitablemente extraña.

En este proceso de integración fueron las formas de distinción por las que valoraban su condición de chilenos donde encontraron los recursos - y si se quiere, la inspiración - para adaptarse a sus nuevas y exigentes circunstancias de vida. Los distintos testimonios del paso de los voluntarios chilenos por los campos de batalla de Cuba delatan que fue la manera como comprendían su identidad nacional uno de los factores que les permitió adaptarse e insertarse en una realidad riesgosa, compleja y llena de incertidumbres. No es difícil suponer que inicialmente casi todos se percibieron muy capaces de asumir las dificultades y sacrificios de una guerra cuya única gratificación era la de contribuir a la independencia de Cuba, si no se perdía la vida en ella. Conforme debieron integrarse a ella, su percepción de ser «caballeros», si bien les permitió interlocultar con quienes los encaminaron hacia la isla, una vez en su suelo también se constituyó en un valor ético vinculado a su identidad nacional. Como chilenos debían comportarse a la altura de una guerra que demandaba una conducta intachable ante los sacrificios que les planteaba, lo que significaba en primer lugar estar a la altura de sus pares cubanos.

Por otra parte, frente al combate también la manera cómo comprendían su identidad nacional operó como un incentivo para conducirse «como chilenos», es decir, como guerreros valientes y decididos, capaces de superar las a veces justificadas desconfianzas de sus compañeros cubanos, demostrando su capacidad de adaptación a un contexto necesariamente ajeno a sus experiencias, mostrando liderazgo y coraje frente a oficiales y tropas que no conocían sus antecedentes y que no obstante reconocieron en ellos jefes susceptibles de ser seguidos. Todo parece indicar - teniendo presente sus asensos, las valoraciones de sus camaradas de armas cubanos, y la percepción que tenían de ellos 
sus compatriotas - que la mayoría fue consecuente con lo que consideraron su impronta nacional.

De esta manera, los voluntarios resignificaron el nacionalismo que los impregnaba, potenciando algunos de sus ingredientes, construidos paradójicamente a partir de una primera guerra donde habían sido los invasores y vencedores de dos países latinoamericanos, y de una segunda donde se habían peleado entre ellos. Con su comportamiento los voluntarios dieron también significado a un americanismo que apelaba más que nada a las experiencias más recientes de sus actores, donde la «patria» los convocaba, los unía, los compelía a combatir, y a buena parte de ellos, a entregar la vida, por la independencia de un país latinoamericano. Si en su país el americanismo no constituía desde hacía mucho tiempo un referente de la política y de las prácticas sociales, y al contrario, se había impuesto un nacionalismo arrogante y hasta despreciativo - sobre todo respecto a sus vecinos-, habían sido algunos de los componentes de este nacionalismo los que los conducirían a comportarse como americanos en unas circunstancias tan especiales y riesgosas, y ante las que solo cabía, para enfrentarlas y superarlas, la fusión de su nacionalismo y su americanismo, haciendo de ambos, uno sólo, para pelear como chilenos en los campos de batalla de Cuba.

\section{ANEXO}

CHILENOS QUE PARTICIPARON EN LA GUERRA DE INDEPENDENCIA CUBANA DE 1895 COMO PARTE DEL EJÉrCITO LIBERTADOR

A lo menos dieciocho chilenos formaron parte del Ejército Libertador cubano. Existe certeza de que así fue pues varios de sus nombres aparecen en los registros de extranjeros del Ejército Libertador consultados por los historiadores Ramón de Armas, César García del Pino y René González Barrios. Además, fuentes chilenas recogen testimonios y noticias de algunos de estos voluntarios. Sin embargo, también la prensa chilena, a través de cartas y entrevistas que publica, puntualmente y de manera escueta recoge la presencia de otros voluntarios, ausentes en los registros cubanos, en donde a veces sólo aparecen sus apellidos: Martínez, Vásquez y Fernández. Los tres serían de los primeros voluntarios en llegar a Cuba y habrían muerto en el curso de la guerra. También P. F. Desmoisnes, en una carta publicada en La Lei el 5 de mayo de 1896, relata el desembarco de cuatro chilenos bajo el mando del coronel cubano Braulio Peña: José D. Lobos, Manuel Aguirre, Timoteo Plaza y Domingo Gaete R. Es muy posible que estos cuatro voluntarios efectivamente participaran en la guerra de 1895. Por ello los hemos incluido en el 
siguiente listado de los chilenos que concurrieron a Cuba, en donde brevemente reseñamos su paso por el Ejército Libertador.

1. Pedro Vargas Sotomayor. Al parecer teniente o capitán de la Armada de Chile. Llegó a Cuba en agosto de 1895. Desde Santiago de Cuba se integra a las fuerzas comandadas por el general Antonio Maceo, con quien participa en la invasión al Occidente de la isla. Fue ascendido al grado de coronel el 22 de septiembre de ese año y al de general de brigada el 8 de abril de 1896. Participó en numerosos combates, siendo altamente estimado por Maceo y la oficialidad que se relacionó con él. Murió por enfermedad en la Provincia de Pinar del Río en 1896. Fue el chileno que más alto grado alcanzó en el Ejército Libertador. (Armas, 1984: 167. González, 2007: 103-121).

2. Arturo Lara. Teniente del Ejército de Chile hasta 1891. En la guerra civil de ese año participa en la batalla de Placilla formando parte de las fuerzas del gobierno de Balmaceda. Desembarca en Cuba el 24 de marzo de 1896 en la bahía de Maraví, al oriente de la isla, en una expedición comandada por el general Calixto García. Alcanza el grado de teniente coronel. Muere en combate en la provincia de Matanzas, el 15 de junio de 1897. (Armas, 1984: 167-168. García del Pino, 1996: 46-48. González, 2007: 79. El Americano, Santiago de Chile, 21 de noviembre de 1895).

3. Manuel Héctor Marcoleta. Capitán del ejército de Chile. En mayo de 1891 es subteniente en el Batallón «Huasco» $11 .^{\circ}$ de línea. En la guerra civil de ese año combate en las batallas de Concón y Placilla en el bando opositor al presidente Balmaceda. En febrero de 1897 es ascendido a capitán en el Batallón n. ${ }^{\circ} 4$ de infantería, en Iquique. Desembarca en Cuba el 24 de mayo de 1897, en Bacuranao, al este de La Habana, bajo las órdenes del comandante Ricardo Delgado. Fue comandante del Regimiento Habana. Murió en octubre de 1897 por enfermedad en el campamento «Montes de oro». [Archivo Histórico del Ejército de Chile, Santiago, (AHECH), tomo 121, 1896, libro Hojas de Vida n. ${ }^{\circ}$ 4, 179 y Lista de Revista de Comisario del Batallón n. ${ }^{\circ} 4$ de Infantería, febrero de 1897. Armas, 1984: 168. García del Pino, 1996: 7071. Dublé, 1900: 195-197].

4. Federico Gabler. Teniente del Ejército de Chile. En 1889 es cadete en la Escuela Militar. En noviembre de 1891 es subteniente del Batallón n. ${ }^{\circ}$ 4, en Iquique. En febrero de 1897 es ascendido al grado de teniente. Desembarca en Cuba junto a Héctor Marcoleta, el 24 de mayo de 1897. Llegó a ser capitán instructor del Regimiento «Habana», Primera Brigada, Segunda División, Quinto Cuerpo, Departamento Occidental. Murió en la Sierra de Ponce en octubre de 1897 por enfermedad. (AHECH, tomo 120, 1896, libro Hojas de Vida, n. ${ }^{\circ}$ 4, 252 y Lista de Revista de Comisario del Batallón n. 4 de 
Infantería, febrero de 1897. Armas, 1984: 168. García del Pino, 1996: 70-71. Dublé, 1900: 85-86).

5. Rubén Machuca. Subteniente del Ejército de Chile. En marzo de 1891 es subteniente del Batallón Cívico Movilizado «Exploradores del Desierto». Al mes siguiente se integra al Regimiento «Chacabuco», 6. ${ }^{\circ}$ de línea, en La Serena. Según la prensa chilena alcanza el grado de capitán en el Ejército Libertador y se reseña que en noviembre de 1895 participa en la batalla de Guantánamo, bajo el mando de Antonio Maceo. También en 1898 la prensa chilena lo señala como uno de los primeros voluntarios en partir a Cuba, y que muere en combate, sin indicar fecha ni lugar. (AHECH, tomo 116, 1985, libro Hojas de Vida n. $^{\circ}$ 6, 232 y Lista de Revista de Comisario del Regimiento «Chacabuco» $6 .^{\circ}$ de línea, junio de 1891. El Americano, Santiago de Chile, 14 de noviembre de 1895. La Tarde, Santiago de Chile, 14 de enero de 1898. La Lei, Santiago de Chile, 26 de julio de 1898).

6. Carlos Dublé Alquizar. Civil. Hijo del coronel de Ejército y diplomático Diego Dublé Almeida. Sin profesión, se dedicaba al comercio en Antofagasta e Iquique. Desembarca en Cuba el 9 de septiembre de 1897, en Boca Ciega, al Este de La Habana. Se integra como soldado a la Primera División, Quinto cuerpo, Departamento Occidental. Alcanza el grado de teniente. Se desempeña como ayudante del mayor general Pedro E. Betancourt. Al término de la guerra es presentado ante Máximo Gómez. De regreso a Chile publica en 1900 el libro En la Manigua, escrito junto al periodista Emilio Rodríguez Mendoza, en donde relata su experiencia durante la guerra. (González, 2007: 96-97. García del Pino, 1996: 74-75. Armas, 1895: 167. Dublé, 1900: 212-213, 215 y 217-218).

7. Carlos Buonocore. Subteniente del Ejército de Chile, al parecer hasta 1891. Desembarca en Cuba el 9 de septiembre de 1897, junto a Carlos Dublé, bajo el mando del brigadier Rafael de Cárdenas. Fue repatriado por gestiones del embajador chileno en Washington. (La Tarde, Santiago de Chile, 19 de julio de 1898. González, 2007: 94-96).

8. Luis Ahumada del Canto. Subteniente del Ejército de Chile, al parecer hasta 1891. Desembarca en Cuba el 9 de septiembre de 1897, junto a Carlos Dublé y Carlos Buonocore, bajo el mando del brigadier Rafael de Cárdenas. (La Tarde, Santiago de Chile, 19 de julio de 1898. García del Pino, 1996: 74-75).

9. Ricardo Elizary López. Sacerdote y abogado, nació en Santiago de Chile. En noviembre de 1894 se avecina en Santiago de Cuba. Posteriormente es nombrado párroco de la Villa de El Cobre y Capellán de la Virgen de la Caridad. En noviembre de 1895 fue encarcelado por los españoles. Libre en abril de 1897, se incorporó al Ejército Libertador el 7 de abril de 1897, con 
treinta y cinco años de edad. Era hijo de Serafín y Encarnación, soltero. Se integró al Regimiento «Baconao», Primera Brigada, Segunda División, Primer Cuerpo, Departamento Oriental. Alcanzó el grado de comandante, auditor de guerra. (González, 2007: 99-100. Armas, 1984: 167).

10. Temístocles Molina Derteano. Teniente coronel del Ejército de Chile, al parecer hasta 1891. Desembarcó en Cuba el 21 de marzo de 1897 en Banes, región de Oriente, en una expedición bajo el mando del general Carlos Roloff. Allí se integró al Regimiento de Infantería «Jacinto», Primera Brigada, Primera División, Tercer Cuerpo, en donde alcanzó el grado de coronel. (Armas, 1895: 166. La Lei, Santiago de Chile, 19 de mayo de 1897).

11. José Lino Varas. Hacia 1891 era oficial del Regimiento "Atacama», según testimonio de Héctor Marcoleta. Desembarca en Cuba junto a Marcoleta y Federico Gabler el 24 de mayo de 1897. No hay otros registros de su estancia en la isla. (La Lei, Santiago de Chile, 27 de junio de 1897).

12. Juan A. Brunet. Tenía veinticinco años al integrarse el Ejército Libertador el 22 de abril de 1897. Era soltero y de profesión mecánico. Alcanzó el grado de teniente. Sirvió en el Regimiento de Infantería «Jacinto», Primera Brigada, Primera División, Tercer Cuerpo, Departamento Oriental. Combatió en la provincia de Matanzas, en la región de Cienfuegos y en Las Tunas (Armas, 1984: 167. González, 2007: 100-101).

13. Francisco Paneque Sánchez. Contaba con veintisiete años de edad al integrarse como soldado al Ejército Libertador, el 11 de agosto de 1895. En los registros cubanos se señala que era hijo de Antonio y Antonia, soltero, y como oficio se indica «del campo». Se incorporó al Regimiento «Tunas», Segunda Brigada, Tercera División, Segundo Cuerpo, Departamento Oriental. (Armas, 1984: 166).

14. José Betancourt Sánchez. De treinta años de edad al momento de incorporarse como soldado al Ejército Libertador, el 2 de septiembre de 1895. En los registros cubanos se señala que era hijo de Felix y Caridad, casado, de oficio «del campo». Sirvió en el Regimiento «Tunas», Segunda Brigada, Tercera División, Segundo Cuerpo, Departamento Oriental. (Armas, 1984: 167).

15. Constantino Varas. Conforme al testimonio de Buonocore tenía el grado de capitán. Operaba en la provincia de Matanzas bajo el mando del teniente coronel Néstor Aranguren. Según Arístides Agüero, herido en combate, fue hecho prisionero por los españoles junto a Buonocore y Ahumada. (La Tarde, Santiago de Chile, 14 de enero y 19 de julio de 1898).

16. Martínez. Se desconoce su nombre. Habría sido uno de los primeros voluntarios en concurrir a Cuba. Conforme a la prensa chilena, tenía una posición cómoda en las salitreras. Alcanzó el grado de mayor dentro del Ejército Libertador. Hacia diciembre de 1895 ya había muerto en combate en 
Taguasco, en la región central de la isla. (El Americano, Santiago de Chile, 22 de diciembre de 1895. La Tarde, Santiago de Chile, 14 de enero de 1898).

17. Vásquez. Se desconoce su nombre. Es mencionado junto a Machuca, Martínez, Sotomayor y Lara como uno de los primeros voluntarios en concurrir a Cuba, en una Declaración publicada en la prensa por la asociación solidaria Sociedad Unión Americana, que desmentía algunos dichos expresados por Buonocore en la entrevista que le hizo La Tarde, el 19 de julio de 1898. (La Lei, Santiago de Chile, 26 de julio de 1898).

18. Fernández. Se desconoce su nombre. Es mencionado por Arístides Agüero como uno de los voluntarios chilenos que murieron en Cuba, en una entrevista publicada en La Tarde. (La Tarde, Santiago de Chile, 14 de enero de 1898).

Finalmente, encontramos los nombres de José D. Lobos, Manuel Aguirre, Timoteo Plaza y Domingo Gaete R. En una carta de P. F. Desmoisnes que publica la prensa chilena los identifica como oficiales del Ejército de Chile. Habrían desembarcado en Cuba en marzo de 1896 en una expedición bajo el mando del comandante Braulio Peña. (La Lei, Santiago de Chile, 5 de mayo de 1896).

\section{BIBLIOGRÁFIA}

Aguirre, Sergio, Raíces y significación de la Protesta de Baragua, La Habana, Editora Política, 1978.

Arancibia Clavel, Roberto, "Chilenos: Civiles y Militares en la Independencia de Cuba", Anuario de la Academia de Historia Miliar, 23 (Santiago de Chile, 2009): 86-103.

Armas, Ramón de, “El apoyo chileno a la Revolución Cubana de 1895; apuntes para la historia del internacionalismo revolucionario en América Latina", Araucaria de Chile, 25 (Madrid, 1984): 147-168.

Cid, Gabriel, La guerra contra la Confederación. Imaginario nacionalista y memoria colectiva en el siglo XIX chileno, Santiago de Chile, Ediciones Universidad Diego Portales, 2011.

Cordoví, Yoel, “La delegación plenipotenciaria en Estados Unidos. Estrategias expedicionarias, 1895-1898", Revista Brasileira do Caribe, XIV/28 (Giás, Goiânia, Brasil, enero-junio 2014): 401-421

Correspondencia Diplomática de la Delegación Cubana en Nueva York durante la Guerra de Independencia de 1895-1898, V vols., La Habana, Publicaciones del Archivo Nacional de Cuba, 1944. 
Dublé, Carlos, En la Manigua, Valparaíso, Imprenta del Universo de G. Helfmann, 1900.

Dublé Urrutia, Diego, Memoria Genealógica de la familia Dublé, Santiago de Chile, Editorial Nascimento, 1942.

Franco, José Luciano, Antonio Maceo, apuntes para una historia de su vida, III vols., La Habana, Editorial de Ciencias Sociales, 3. ${ }^{a}$ ed., 1989.

García del Pino, César, Expediciones de la Guerra de Independencia. 1895-1898, La Habana, Editorial de Ciencias Sociales, 1996.

González Barrios, René, Chile en la independencia de Cuba, La Habana, Casa Editorial Verde Olivo, 2007.

Historia del Ejército de Chile, VII vols., Santiago de Chile, Estado Mayor General del Ejército, 1985.

Hostos, Eugenio María de, Obras Completas, Edición conmemorativa del gobierno de Puerto Rico, 1839-1939, XX vols., La Habana, Cultura S. A., 1939.

Ibarra, Jorge, José Martí, dirigente político e ideólogo revolucionario, La Habana, Editorial de Ciencias Sociales, 1980.

Ibarra, Jorge, "La Guerra del 95: ¿la guerra de la voluntad y del ideal o de la necesidad y de la pobreza?", Historia y memoria: sociedad, cultura y vida cotidiana en Cuba. 1878-1917, La Habana, Centro de Investigación y Desarrollo de la Cultura Cubana Juan Marinello, Programa de Estudios de América Latina y el Caribe, Instituto Internacional, Universidad de Míchigan, 2003: 35-53.

López Muñoz, Ricardo, "Un chileno insurrecto en la colonia española de Cuba: su testimonio oral, cien años después", Boletín de Historia y Geografía, 11 (Santiago de Chile, 1994): 91-100.

Mc Evoy, Carmen, “¿República nacional o república continental? El discurso republicano durante la Guerra del Pacífico, 1879-1884", Carmen Mc Evoy y Ana María Stuven (eds.), La República Peregrina: Hombres de armas y letras en América del Sur. 1800-1884, Lima, IEP-IFEA, 2007.

Mc Evoy, Carmen, Guerreros civilizados. Politica, sociedad y cultura en Chile durante la Guerra del Pacífico, Santiago de Chile, Ediciones Universidad Diego Portales, 2011.

Mesa García, Raúl, "El general chileno Pedro Vargas Sotomayor: maestro de Mambises”, SudHistoria, 3 (Santiago de Chile, julio-diciembre 2011): 54-71.

San Francisco, Alejandro, "La excepción honrosa de paz y estabilidad, de orden y libertad'. La autoimagen política de Chile en el siglo XIX”, Gabriel Cid y Alejandro San Francisco, (eds.), Nación y nacionalismo en Chile. Siglo XIX, 2 vols., Santiago de Chile, Centro de Estudios Bicentenario, 2009: 55-84. 
Sánchez Abadía, Silvia, "Olvidos de una guerra: el coste humano y económico de la independencia (Cuba-España, 1895-1898)”, Revista de Indias, LXI/221 (Madrid, 2001): 113-140.

Subercaseaux, Bernardo, "Pensamiento operante y escenificación del tiempo histórico”, Eduardo Cavieres (ed.), Entre discursos y prácticas. América Latina en el siglo XIX, Valparaíso, Pontificia Universidad Católica de Valparaíso, 2003: 47-69.

Subercaseaux, Bernardo, Historia de las ideas y de la cultura en Chile, 3 vols., Santiago de Chile, Editorial Universitaria, 2011.

Torres-Cuevas, Eduardo y Loyola Vega, Oscar, Historia de Cuba. 1492-1898. Formación y liberación de la nación, La Habana, Editorial Pueblo y Educación, 2. ${ }^{\mathrm{a}}$ ed., 2002.

Zamora, Bladimir (comp.), Papeles de Panchito, La Habana, Editora Abril, 1988.

Zanetti, Oscar, Historia mínima de Cuba, México, El Colegio de México/Turner, 2013.

Fecha de recepción: 16 de diciembre de 2014.

Fecha de aceptación: 23 de julio de 2015.

\section{Nationalism and Americanism among Chilean volunteers in the Cuban Army of Liberation during the Second War of Independence (1895-1898)}

The war of independence of Cuba from 1895-1898 mobilized a large contingent of Chilean volunteers to the island, willing to fight alongside the rebels. From documentaries, periodicals and literature - from Cuban and Chilean sources - this paper analyses the motivations and circumstances that summoned them and how they adapted and legitimized themselves in a war that they adopted as their own, despite being foreigners. While an Americanist culture underlies their departure and behavior, it was the redefinition of a renewed nationalism that emerged within the complex situation in Chile during the period preceding the Antillean conflict, which allowed them, most of the time, to be recognized as legitimate fighters by their superior officers and by the troops they commanded.

KeY wORDs: Chilean Americanism; solidarity with Cuba; Chilean self-perception; Independence of Cuba. 